\title{
Vocabulary Learning through Duolingo Mobile Application: Teacher Acceptance, Preferred Application Features and Problems
}

\author{
Alsaif Sarah Ali M, Farhana Diana Deris
}

\begin{abstract}
Vocabulary learning is vital towards acquiring new languages and therefore insufficient vocabulary knowledge can be considered a significant barrier to such learning. Availability of tools to enhance or simplify the learning process is an added advantage to encourage learners to learn new languages. This research was conducted to investigate teacher acceptance of mobile applications in Saudi Arabian universities for vocabulary learning, identify suitable features for vocabulary learning applications and to identify problems that may arise through use of mobile applications in classroom settings with the aim of solving them. Duolingo mobile application was employed as a study tool to investigate effectiveness of the applications and their technological features. Twenty English language teachers participated in the study by answering questionnaires and three of them were also interviewed and resulting data analyzed quantitatively and qualitatively. The main findings from the research are that teachers showed positive attitudes towards teaching and learning using vocabulary learning applications and that several challenges faced by users inform on unsuitability of the applications and reluctance to use by teachers. Therefore, appropriate measures should be taken to address the problems associated with use of mobile applications in vocabulary learning and teaching so as to explore the vast potentials they have towards learning.
\end{abstract}

Index Terms: Duolingo app, Mobile applications, Teacher's acceptance, Vocabulary learning

\section{INTRODUCTION}

Learning vocabulary of a new language is often challenging for many people who may feel discouraged because of the overwhelming amount of words to be learned (Nation, 2001). Self-directed learning presents the most effective means of learning new languages especially where the language is a second language for the majority of people around. Therefore, it is imperative to develop effective ways to understand the language patterns and also use the best available methods for vocabulary learning (Chen, Hsieh, and Kinshuk, 2008). Vocabulary learning is the process of acquiring vocabulary of a second language as building blocks for the mastery of the language. The purpose of vocabulary learning is to memorize and use the acquired words in

Revised Manuscript Received on September 22, 2019.

Alsaif Sarah Ali M, School of Education, Faculty of Social Sciences and Humanities, Universiti Teknologi Malaysia, 81310 UTM Johor Bahru, Johor, Malaysia

Farhana Diana Deris, Language Academy, Faculty of Social Sciences and Humanities, Universiti Teknologi Malaysia, 81310 UTM Johor Bahru, Johor, Malaysia (Email: diana@utm.my)

various contexts of conversation that may arise (McCarthy, 1984; Teng, 2016). However, vocabulary learning can be very difficult with

most conventional learning models that focus on deliberate classroom learning as opposed to the potential of incidental learning with technology.

\section{A. Background of Problem}

The emergence of technology has unprecedentedly revolutionized the process of learning new languages. For instance, auditory learners can listen to audio materials in the new language (Cohen and Wolvin, 2011), kinesthetic learners can play vocabulary games on digital devices and visual learners can watch informative videos about the language (Kim et al., 2012). Various technological platforms can allow learners to contextualize vocabulary in ways that are more effective than just memorization (Pachler, Bachmair, and Cook, 2010) and as a result, there have been calls to incorporate mobile devices for language learning within school settings (Ali and Ghazali, 2015; Ali and Ghazali, 2016). Mobile Assisted Language Learning (MALL) has shown to be an innovative and interactive means with which students can learn second languages incidentally. Mobile phones and other portable digital devices are convenient for self-directed or incidental learning and for other language acquisition methods like games that improve spelling and vocabulary acquisition (Prenskey, 2005; Stockwell, 2007). Such student-centered learning approaches that enable student to learn at any time they are interested in and in an interactive manner instill the right attitudes in students towards learning a new language (Soleimani, Ismail, and Mustaffa, 2014).

It is undeniable that the future of learning new languages effectively is tied to mobile technology but the many problems associated with mobile use in classrooms influence reluctance by teachers to incorporate them as vocabulary learning tools. Moreover, various features of mobile devices and the installed vocabulary learning applications greatly determine suitability for them to be used for educational purposes (Nielsen and Budiu, 2013). There are many mobile applications already in use by learners interested to learn new languages incidentally and improve their vocabulary acquisition.

This research therefore analyzed the use of mobile technology to enhance

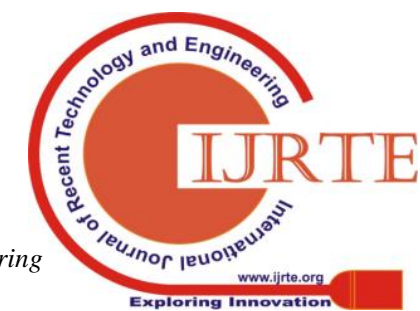


vocabulary learning by investigating factors that influence their acceptance amongst teachers as well as ways of improving them to be more suitable as educational tools (Thomas and O'Bannon, 2013).

\section{B. Problem Statement}

Mobile phone use has spread universally allowing them to be increasingly used in schools. Mobile application developers have come up with appropriate software such as Duolingo, Google Translator and Busuu that help enrich language experience for learners. Even though numerous technologies such as video lessons have been widely accepted by teachers, the teachers have been reluctant to incorporate mobile phones for learning purposes citing distraction (Abas, Peng and Mansor, 2009; Beland and Murpgy, 2015). Even though social media has increasingly become popular among young people, most of them do not focus on educative aspects and may also be unaware of vast educational opportunities mobile technology possesses towards enhancing vocabulary learning. Some teachers who are aware of these opportunities neglect them because they lack a detailed understanding of their effectiveness and efficiencies (Herro et al., 2013). Technological challenges like small screen interface that strain learners, quickly graining batteries and low Random Access Memories (RAM) that slow or deadlock phone processes when the phone is burdened by large sized applications make mobile phone unsuitable for use (Sweeney and Creastani, 2006). Various social implications like phones as a statement of class, pressure on parents to buy newer trendy devices and incidences of cyber bullying have also been cited as reasons for teacher reluctance to use mobile phones for learning (Juvonen and Gross, 2008).

The lack of research in spirituality in the Malaysian school context has created a gap between the understanding of workplace spirituality's potential in contributing to school effectiveness and culture (Abdullah, Kanesan, et al., 2009). There are many cases that relates to counterproductive work behaviour has been reported. Also, we can see that, there is many studies have been conducted on the antecedents of employee counterproductive work behaviour but, fewer studies have focused on the influence of workplace spirituality on deviant behaviour (Noraida, 2011). Thus, this study will investigate the relationship between workplace spirituality and counterproductive work behaviour among lecturers in Universiti Teknologi Malaysia (UTM)

\section{The research objectives are: -}

i. To identify teachers' acceptance (or reluctance) towards the use of Duolingo mobile applications in learning vocabulary.

ii. To determine the preferred features for vocabulary learning mobile applications.

iii. To examine the possible obstacles that will rise through using Duolingo applications in the classroom.

\section{RESEARCH METHODOLOGY}

The research investigated suitability of mobile phone application Duolingo to promote vocabulary learning through assessment of teacher acceptance, appropriateness of features and related their related problems. To assess the level of acceptability or reluctance by teachers, nature of mobile application features that would be ideal for class settings and problems associated with the technology, the researcher employed interviews and structured questionnaires to obtain relevant information from instructors. Questionnaires were assigned to all participants but interviews were conducted with three carefully identified instructors. Questionnaires and interviews were identified as the best research instruments for this particular study because they offered best avenues for investigating teacher perceptions on Duolingo app from their own accounts (Boynton and Greenhalgh, 2004).

Twenty college instructors from across major Saudi Arabian colleges were selected and agreed to participate in the study. The participants in the study were all female and aged between 23 and 42 years of age. Their knowledge and experiences in using the Duolingo app were assessed to establish their attitudes towards using the applications in classroom settings, useful applications and related problems. Therefore, the research tools were designed to address the three key factors under investigation. They were selected through purposive sampling followed by a preliminary survey to identify the most suitable instructors based on experience, educational requirements and number of students they handle annually (Mackey and Gass, 2015). All of them were given a set of questionnaires to respond to while three were selected for detailed interviews based on their specialty, level of interaction with students and level of understanding of the Duolingo application (Brinkmann, 2014).

All participants were required to use the Duolingo mobile application at least a week prior to taking part in the exercise. Instructors that participated in the interviews were believed to be more familiar with the application and its operation and how its features may impact vocabulary learning. Qualitative and quantitative designs were employed and to advance qualitative aspects, participants for investigation of some important elements of the research were not predetermined to enhance quality of information that fully responds to areas being investigated (Sargeant, 2012; Gentles et al., 2015). Participants were verbally asked for their consent to participate and assist in the study and they could opt out at any time of their convenience. The research was approved by ethics committee based on its design and researcher compliance with requisite procedures.

Questionnaires contained 37 items divided within four main sections: A - demographics of participants, B adaptations from previous researches and theoretical foundations of MALL,

C - features of language learning applications and D - 
participants' experience in using mobile applications in vocabulary learning. All items of the research tools were designed and developed by the researcher and applied both open-ended and closed-ended questions that allowed flexibility of information provision where necessary. The content of the survey was validated by a team of seven ESL and educational technology university professors. Several evaluation sessions were conducted and layout and content of the questionnaires improved based on feedback from the experts. Validation and evaluation by experts were done to ensure the tools used were appropriate for meeting research goals and measuring variables important for the study (Walker, 2011).

The research procedure entailed participants being taught how to use the application and a one-week period to familiarize with it. Questionnaires were then given and responses analysed based on supportive and meaningful responses of interviews. Questionnaires provided detailed information and data that were designed to respond to important elements being investigated while the interviews served to augment information gathered from the questionnaire analysis because interview information were obtained from instructors well conversant with Duolingo app and its features. Analysis of the collected data was based on the research questions of the study. Analysis was done using SmartPLS program to provide quantitative analysis (Ringle, Wende and Will, 2017). SmartPLS was most suitable for the analysis because of its analysis convenience to obtain quantifiable meaning from qualitative information. Demographic data in Section A of questionnaire was analysed using descriptive statistics with parameters like averages and standard deviation. For interviews, the responses were transcribed and analysed through thematic coding to create a framework for the research and to protect interviewee privacy (Taylor, Bogdan, and DeVault, 2015).

\section{DATA ANALYSIS}

The study included 20 participants; 20 females aged between 23 and 42 years. This number represented those identified instructors who confirmed interest in participating in the study and who actually proceeded to fill the questionnaires and or take part in the interviews. The majority of the participants were between the ages of $23-32$ (85\%) and the rest between 33 and 42 (15\%). Ages older than 42 were not represented in the study sample indicating interest amongst younger instructors to explore the impact mobile applications may have on learning. Fourteen (70\%) of the participants had a teaching experience period of between $1-5$ years, $4(20 \%)$ less than a year and $2(10 \%)$ more than 5 years teaching experience. With older teachers not taking part in the research, it was expected that the level of experience would counter-represented in the sample.

All but one participant attested to having used mobile applications to learn vocabulary $(95 \%)$. This shows how widely used mobile applications are in learning and how they are relatively known. Frequency of using mobile applications was also investigated and its was established that 40\%, 30\%,
$10 \%$ and $20 \%$ used them once, twice, thrice and more than four times every day, respectively. Teachers may be aware of and use the mobile applications but the frequency of use is shown to be minimal for a majority who took part. This may indicate the applications are selectively used if it is for learning purposes. Half of respondents accessed the mobile application in the mornings and at nights while only $25 \%$ access them in the afternoons and $45 \%$ in the evenings. Periods when the participants are expected to be away from school [(arriving (mornings), leaving (evenings) or already at home (nights)] are the preferred times to use the applications.

To measure the extent of teacher acceptability/reluctance, the study sought to establish their perspectives on how the mobile applications facilitate the vocabulary learning process. $90 \%$ believed that mobile phones facilitate learning, $80 \%$ feel the applications provide an interactive learning environment, $90 \%$ said multimedia in the applications are useful for English as Second Language (ESL) learning, while $75 \%$ agreed that scaffolding can be provided for individual learners using mobile phone for teaching. These statistics may imply that the mobile applications' use for teaching and learning purposes is an effective method that can be employed successfully. $90 \%$ said phone applications can be used to teach different language skills in ways that are cost effective $(65 \%)$ and time efficient $(75 \%) .95 \%$ believed that the applications provide ubiquitous language learning opportunities though opinion was split over access to internet connectivity for users (50\%). 70-85\% felt confident to use the applications in classroom settings and expressed confidence in ability to design MALL activities as well as adapt them to their teaching techniques. From sampled participant responses, it was established that the mobile applications such as Duolingo for learning purposes are beneficial towards helping learners improve vocabulary. The responses can be grouped into four broad categories of useful findings: convenient and effective, interactive learning, promotion of new vocabulary acquisition and that their use is interesting and motivating. Convenience and effectiveness are attributed to the ease with which the applications can be used at any time the learner wishes as opposed to books that may be inaccessible at some times. The applications are interesting and motivating because they add enjoyment in classrooms and students will be interested to learn vocabulary in ways that are fun. The applications promote vocabulary acquisition because they offer wide varieties of learning tools for explanation, consulting, pictorials and ability to readily access other assistive technology like dictionaries, etc. The tools are interactive because students explore more learning options as opposed to traditional classroom settings of deliberate learning.

Teachers listed applications they had used during their lessons in order to point out the ones they found most useful for inclusion in appropriate learning models.

$$
\begin{aligned}
& \text { The majority of them }(75 \%) \\
& \text { and }(70 \%) \text { identified "Media" } \\
& \text { and "Words list with } \\
& \text { Published By: } \\
& \text { Blue Eyes Intelligence Engineering } \\
& \text { \& Sciences Publication }
\end{aligned}
$$


definition and examples", respectively, as the most useful features followed by "Test/Quiz" (65\%), "Resource" (65\%), and then "Game" (60\%). Other features such as "Bookmark/Favorite words" (35\%), "Notification" (45\%) and "Words' level of difficulty" (45\%) were least favored by the participant instructors as useful vocabulary learning tools. These represent all Duolingo features which imply that all features are appropriate for classroom use, Duolingo is an appropriate vocabulary learning tool and that the most popular features from the study ought to be incorporated in any mobile applications intended for vocabulary learning.

\section{DISCUSSION}

\section{A. Participants}

The research participants were entirely female and this can be explained by many factors. For instance, it was difficult to approach male instructors due to strict Saudi policies that segregate male and female instructors completely (Alsadoon, 2012). Moreover, female teachers influenced each other to take part in the study due to common interests about the topic under study. Preference to take part in the study for younger instructors as shown by $85 \%$ of participants being between 23 and 32 years shows that younger teachers most probably interested in integrating technology in the classroom. As such, they had a greater desire to participate in a study related to using mobile phone applications for vocabulary learning. Moreover, the age group is more likely to be familiar with MALL than older individuals. With $95 \%$ of participants reporting to having used mobile applications for vocabulary learning and with frequency of users up to $20 \%$ of participants, it is evident that the teachers are appreciably aware of the applications and their potential as vocabulary learning tools and indeed use them to a great degree of frequency. Considering that half of the respondents expressed that mornings and nights were the most convenient times to use the applications, it may prove that using mobile applications for vocabulary acquisition may be a perfect way to explore incidental learning and support scheduled class learning. Unpopularity of their use during the day may also imply reluctance to use them in class setting which most of the time occur during the day.

\section{B. Usefulness of mobile applications in vocabulary learning}

Majority of participants (95\%) expressed confidence in mobile applications as tools for vocabulary learning in class settings saying they actually assist in learning multiple languages and can be successfully incorporated into their teaching styles/techniques/models. Similarly, a study by Brebera (2017) showed up to $75 \%$ of teachers used mobile phone applications voluntarily or as instructed due to their belief in the applications' potential. This shows that the applications are widely accepted for teaching and learning purposes and that they are indeed useful tools. Evidently, teacher perceptions are positive on use of the applications for vocabulary learning and this may be a significant factor informing on their acceptance or reluctance to incorporate them in their classrooms. From the findings, the mobile applications for vocabulary learning are proven to be beneficial towards improving vocabulary because they are convenient, effective, interesting, interactive, motivating and they actually promote vocabulary acquisition (Fauzi, 2018).

\section{Advantages of using mobile applications for vocabulary learning}

Mobile phone applications can be used at any time the learner finds comfortable and provide most of learning requirements and experiences the learner may find more motivating than restricted classroom settings (Turloiu and Stefánsdóttir, 2011). For instance, there may be limited books available on some language instructions or their specific topics of interest and this makes it difficult for the learner to access them. Moreover, books may be uncomfortable to carry around compared to phones containing the learning applications and online interaction platforms (Heil et al., 2016). Scaffolding may also be provided to each learner by using mobile phones. Scaffolding is used here to refer to the ability of phone to be used to support other classroom learning material. Most respondents in this research believe that mobile applications can support learning and this may be because they feel the devices can support learning through appropriate scaffolding structures. Even though the devices support learning through scaffolding which will be provided to all learners the role of teachers cannot be completely substituted (Ahmed, 2016).

Using technology for learning process is an essential part of interactive learning which is appropriate for the current generation of young people. Most young people are familiar with various technological aspects including gadgets, applications, and social media and therefore will most certainly embrace the idea of including them for learning purposes (Butgereit and Botha 2009). They can use them to research on various vocabulary acquisition aspects and also to consult teachers and peers on areas of difficulty as well as to practice acquired technology in fun and interactive ways. Mobile applications for vocabulary learning such as Duolingo offer fun and enjoyable means to explore a language. Such fun encounters may be appealing to the learners, especially younger ones who will always try to open them and learn more vocabulary whenever they have some free time. Various feature like "test/quiz" may be more applicable in such instances allowing the learners to recap their last learning sessions.

Learning second language vocabulary may be overwhelming for some learners and using interactive and fun applications at their convenience may be the motivation they require to embrace learning the language (Nagy, Herman, and Anderson, 1985). Young people are excited by fun classroom activities and are more likely to pay attention or simply show interest in what is being taught if the process is fun as in the case of using mobile applications for learning. Since the phone applications have numerous features available within it or within

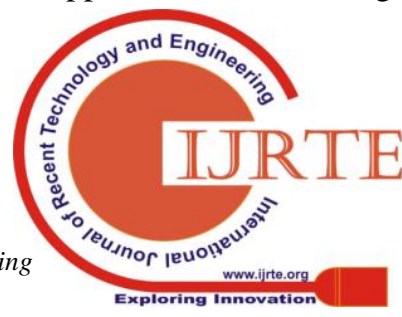


the same device (where other applications may support primary vocabulary learning application),

the tools ensure improved vocabulary acquisition as opposed to restrictive traditional classroom settings (Asgari and Mustapha, 2011). The above discussed factors indicate that teachers generally approve of mobile applications' use for learning and as Thornton and Houser (2005) elaborate, they are the reasons why mobile applications should be adopted into instruction models for teaching vocabulary.

\section{Challenges of mobile applications as learning tools}

The ease with which the applications can be used ensures that they cannot discourage use by learners. However, some instances make it difficult for a learner to acquire information about languages they are interested to learn or the nature of the application make it difficult to accommodate the learning process (Johnson et al., 2016). One challenge is possession of the phones which may be a problem in poor developing countries since not all people, especially young people, have access to mobile phones. Brebera (2017) also points out that subjects taught by teachers were important indicators of teacher perceptions of their suitability for classroom inclusion. Moreover, internet access may also be a problem to most classroom settings or learner's free time leading to the applications impossible to use. These challenges based on inaccessibility of the applications to most learners may be difficult to resolve (Pilar, Jorge, and Cristina, 2013).

Besides problems of inaccessibility, classroom processes are more likely to be disrupted by mobile phone use either through student behavior or their attitudes. Hockly (2012) reported that using mobile applications in classroom settings can lead to loss of teacher's authority in the class and it becomes an issue of great concern. This statement is reiterated by one of the instructors interviewed for this research, Gia (coded name), who explains that students may undermine teacher's authority "because allowing students such freedom leads to distraction in class which will be reflected in their performance in class". There are also various aspects of costs that need to be factored in including cost of integrating the technology into classrooms and that of training teachers to use them effectively (Bates and Sangra, 2011). Finally, it is difficult to control phone use especially if they are owned by the learners and Cojocnean (2016) predicts that this interference may be curbed through ownership by a school district.

\section{E. Preferred features for mobile applications' use}

All Duolingo application features were listed by the instructors in the questionnaires as being useful for vocabulary learning in classroom settings. This implies that Duolingo is an ideal mobile phone application for use in vocabulary learning and teaching. Finding all of the features useful for class settings shows its appropriateness because any feature that would have been ignored would mean reluctance by the teachers to use the application for learning purposes (Mayer, 2003). Identification of most preferred features including "media", "words list with definition and examples", "test/quiz", resources and "games" may be insightful in pointing to features interested institutions may want to incorporate in their teaching models.
Applications features like "games" and "notifications" may be disruptive (Mayer and Moreno, 1998) but 'gamified' applications have been proven to be fun for learners thus helpful (Baldauf, Brandner, and Wimmer, 2017). Least favored features such as "notification", "bookmark/ favorite words" and "words' level of difficulty" may indicate features that may be removed from future application development or improved to align them with teachers' demands. From this study, it is evident that Duolingo is a prototype of appropriate mobile phone applications suitable for use in vocabulary learning even in classroom settings. Policy makers and application developers may find this information helpful in ensuring future vocabulary learning is made easier and more interesting through incorporating mobile applications and their features like Duolingo in vocabulary learning sessions.

\section{CONCLUSIONS}

With the rise in use of technology especially amongst the youth, there is need to explore the potential of mobile phone applications to advance learning for vocabulary acquisition. Learning a new language can be very overwhelming and since using Mobile-Assisted Language Learning (MALL) helps to ease the problems, learning institutions should consider incorporating them into their teaching and learning models/ styles (Alavinia, and Qoitassi, 2013). Using mobile phones in classroom settings is very challenging and may compromise the quality of learning and disrupt the whole process because the phones could be a distraction. There is need to improve the applications in ways that they become useful in classrooms or students' free time without compromising the learning process.

Mobile applications for vocabulary learning offer numerous advantages including; their interactive nature, introducing fun into the classroom and allowing learners enjoy the learning process, motivating learners to continue learning and acquiring vocabulary of the new language despite challenges, providing a variety of avenues and features to broaden learning beyond traditional classroom settings, and their convenience and effectiveness of use at all times when the student feels comfortable to learn (Basal et al., 2016). These advantages should be exploited and if done correctly, difficulties in learning new languages and sustaining such endeavors can be overcome. Nonetheless, more needs to be done to tackle the associated challenges of using the applications in classroom settings.

Challenges making use of mobile applications like Duolingo difficult to incorporate into classroom settings include; social pressure to remain trendy and obtain newer gadgets, expenses involved in installing the technology systems in school, difficulty in controlling students using their own phones, classroom interruptions and loss of control by teachers and also technological shortcomings such as small RAM sizes to handle large applications files (Johnson et al., 2016). These challenges can be overcome by using research such as this to inform on development of better applications and features compatible with desirable teaching models. Duolingo 
seems to be an appropriate learning tool that policy makers and institutional heads ought to try out.

Advantages and challenges of using the mobile applications for learning purposes are vital indicators of teacher acceptance or reluctance to use them in classroom settings. Various features within the specific applications as well as type of subject being taught also advice on suitability to incorporate them into vocabulary learning sessions (Budiu \& Anderson, 2001). Overall, teachers' perceptions on the use of the applications for vocabulary learning is positive provided they are developed to be more suitable. Software designers and developers may explore various features of the applications and align them with available knowledge on classroom practices to ensure their optimal benefits. Policy makers also have a role to play in overcoming challenges by facilitating their installations and promoting further research (Yusri, Goodwin, and Money, 2015).

This study established that teachers are generally aware and have used mobile applications for learning or teaching vocabulary of new languages and are more willing than reluctant to apply them in their classes. Reasons for reluctance to use them are mainly based on the features of the application and if properly developed, teacher acceptance should not be a problem. Preferred features were found to be those that promote memorization and mastery of new vocabularies such as "tests/ quiz" and "words list with definition and examples" and application developers can work with various stakeholders to improve them. Finally, the research established that barriers/ obstacles to using mobile applications for learning purposes stem from disruptions and limited control by teachers. Appropriate measures can be taken to ensure the challenges are addressed.

This research was successful in advancing knowledge and addressing gaps in language acquisition and education and its findings are pertinent for solving vocabulary learning challenges. Using mobile applications for learning purposes is a fun and interactive adventure that offers better learning outcomes compared to strict traditional classroom approaches that do not offer enough options for learners. Future researchers on the subject may focus on students/ learners' perspectives and compare them with teachers' perspectives addressed herein. Other applications that Duolingo can also be used for research to establish suitability and the researchers may also consider developers to establish best ways of improving application features.

\section{REFERENCES}

1. Abas, Z. W., Peng, C. L., \& Mansor, N. (2009). A Study on Learner Readiness for Mobile Learning at Open University Malaysia. IADIS International Conference Mobile Learning. 151-15.

2. Ahmed, H. B. E. (2016). Duolingo as a Bilingual Learning App: A case study. Arab World English Journal, 7(2), 255-267.

3. Alavinia, P., \& Qoitassi, K. (2013). On the Viability of Vocabulary Learning Enhancement Through The Implementation of MALL: The Case of Iranian EFL Learners. Journal of Language Teaching \& Research, $4(2), 412-426$.

4. Ali, Z., \& Ghazali, M. (2016) VocBlast: A qualitative Evaluation on the use vocabulary mobile app from teachers' views. 1st Global Conference on Technology in Language Learning
5. Ali, Z., \& Ghazali, M. (2015). Learning Technical Vocabulary through a Mobile App: English Language Teachers' Perspectives. International Journal of Language Education and Applied Linguistics (IJLEAL). 4, 81-91.

6. Alsadoon, H. S. (2012). Use of Cell Phones In Education at King Saud University In The Kingdom of Saudi Arabia. ProQuest Dissertations Publishing. (Doctoral Dissertation). Ohio University, Ohio, OH.

7. Asgari, A. \& Mustapha, A. B. (2011) The Type of Vocabulary Learning Strategies Used by ESL Students in University Putra Malaysia. English Language Teaching 4(2): 84-90.

8. Baldauf, M., Brandner, A., \& Wimmer, C. (2017). Mobile and gamified Blended Learning for Language Teaching: Studying Requirements and Acceptance by Students, Parents and Teachers in The Wild. In Proceedings of the 16th International Conference on Mobile and Ubiquitous Multimedia (pp. 13-24). ACM.

9. Basal, A., Yilmaz, S., Tanriverdi, A., \& Sari, L. (2016). Effectiveness of Mobile Applications in Vocabulary Teaching. Contemporary Educational Technology. 7(1), 47-59.

10. Bates, A. and Sangrà, A. (2011) Managing Technology in Higher Education San Francisco: Jossey-Bass/John Wiley and Co. ISBN:978-84058472-9.

11. Beland, L.-P., \& Murphy, R. (2015). Ill Communication: Technology, Distraction \& Student Performance. Centre for Economic Performance (EP) (No.1350). Discussion Paper

12. Boynton, P. M., \& Greenhalgh, T. (2004). Hands-on Guide to Questionnaire Research: Selecting, Designing, and Developing Your Questionnaire. BMJ: British Medical Journal, 328(7451), 1312.

13. Brebera, P. (2017). Microlearning in Foreign Language Courses: A Threat or a Promise?. In European Conference on e-Learning (pp. 85-93). Academic Conferences International Limited.

14. Brinkmann, S. (2014). Unstructured and Semi-Structured Interviewing. In P. Leavy (Ed.), The Oxford Handbook of Qualitative Research (pp. 277-299). Oxford: Oxford University Press.

15. Budiu, R. \& Anderson, J.R. (2001), "Word Learning in Context: Metaphors and Neologisms", Tech. Rep. CMU-CS-01-147 (Carnegie Mellon Univ., School of Comp. Sci.).

16. Butgereit, L., \& Botha, A. (2009, May 06-08). Hadeda: The Noisy Way to Practice Spelling Vocabulary Using a Cell phone. Paper presented at the IST-Africa 2009 conference, Kampala, Uganda. Calder, J. (1998) Survey research method. Medical Education, 32(1998), 638-652.

17. Chen, N. \& Hsieh, S. \& Kinshuk. (2008). The Effects of Short-term Memory and Content Representation Type on Mobile Language Learning. Journal of Learning and Technology, 12, 93-113.

18. Cohen, Steven D. \&Wolvin, Andrew D. (2011) Listening to Stories: An Initial Assessment of Student Listening Characteristics. Listening Education, 2/2011 pp. 16-25.

19. Cojocnean, D. (2016). Factors Determining Students' Low Usage of Mobile Tools inTtheir English Vocabulary Learning. PORTA LINGUARUM, 31-43.

20. Fauzi, A. R. (2018). The Effectiveness of Duolingo In Improving Vocabulary Ability At The Sixth Grade Of Madrasah Ibtidaiyah Darul Ilmi Banjarbaru School Year 2017/2018.

21. Gentles, S. J., Charles, C., Ploeg, J., \& McKibbon, K. A. (2015). Sampling in qualitative research: Insights from an overview of the methods literature. The Qualitative Report, 20(11), 1772.

22. Heil, C. R., Wu, J. S., Lee, J. J., \& Schmidt, T. (2016). A Review of Mobile Language Learning Applications: Trends, Challenges, and Opportunities. The Eurocall Review, 24(2), 32-50.

23. Herro, D., Kiger, D., \& Owens, C. (2013). Mobile Technology: Case-based Suggestions for Classroom Integration and Teacher Educators. Journal of Digital Learning in Teacher Education, 30(1), 30-40. doi:10.1080/21532974.2013.10784723

24. Hockly, N. (2012). Mobile Learning. Elt Journal, 67(1), 80-84

25. Johnson, A. M., Jacovina, M. E., Russell, D. E., \& Soto, C. M. (2016). Challenges and Solutions When Using Technologies In The Classroom. In S. A. Crossley \& D. S. Mcnamara (Eds.) Adaptive Educational Technologies For Literacy Instruction (Pp. 13-29). New York: Taylor \& Francis. Published with acknowledgment of federal support.

26. Juvonen, J., \& Gross, E. F. (2008). Extending The School Grounds? -Bullying Experiences in Cyberspace. Journal of School Health, 78(9), 496-505.

27. Kim, M. et al. (2012). Evaluating Multisensory Learning System for Teaching English Intonation. Human Centric Technology and Service in Smart Space. Springer Netherlands. 182: 43-50.

28. Mackey, A., \& Gass, S. M. (2015). Second Language Research. Methodology and Design. Routledge.

29. Mayer, R. (2003). Multimedia learning. Cambridge: Cambridge University Press. 
30. Mayer, R., \& Moreno, R. (1998). A Split-Attention Effect In Multimedia Learning: Evidence for Dual Processing Systems In Working Memory. Journal of Educational Psychology, 90(2), 312.

31. McCarthy, M. (1984). A New Look at Vocabulary In EFL. Applied Linguistics, 5, 12-22.

32. Nielsen, J., \& Budiu, R. (2013). Mobile Usability. MITP-Verlags GmbH \& Co. KG.

33. Nagy, W. E., Herman, P., \& Anderson, R. C. (1985). Learning Words From Context. Reading Research Quarterly, 20, 233-253.

34. Nation, I. (2001).Learning Vocabulary In Another Language. Cambridge: Cambridge University Press.

35. Pachler, N., Bachmair, B., Cook, J. (2010). Mobile Learning. Structures, Agency, Practices. London: Springer.

36. Pilar, R. A., Jorge, A., \& Cristina, C. (2013). The Use of Current Mobile Learning Applications In EFL. Procedia-Social And Behavioral Sciences, 103, 1189-1196.

37. Prenskey, M. 2005. What can You Learn Srom A Cell Phone? Almost Anything! The Innovative Gateway 1 (June/July).

38. Ringle, C. M., Wende, S., \& Will, S. (2017). Smart PLS v. 3.2. 6. SmartPLS, Hamburg.

39. Sargeant, J. (2012). Qualitative Research Part II: Participants, Analysis, and Quality Assurance. Journal of graduate medical education, 4 1, 1-3.

40. Soleimani, E., Ismail, K., \& Mustaffa, R. (2014). The Acceptance of Mobile Assisted Language Learning (MALL) among Post Graduate ESL Students in UKM. Procedia Social and and Behavioural Sciences. 118 457-462.

41. Stockwell, G. (2007). Vocabulary On The Move: Investigating An Intelligent Mobile Phone-Based Vocabulary Tutor. Computer Assisted Language Learning, 20(4), 365-383.

42. Sweeney, S. \& Crestani, F .(2006). Effective Search Results Summary Size and Device Screen Size: Is There A Relationship?, Information Processing and Management, 42 (4), pp. 1056-1074.

43. Taylor, S. J., Bogdan, R., \& DeVault, M. (2015). Introduction to Qualitative Research Methods: A Guidebook And Resource. John Wiley \& Sons.

44. Teng, F. (2016). The effects of context and word exposure frequency on incidental vocabulary acquisition and retention through reading. The Language Learning Journal, , 1-14. doi:10.1080/09571736.2016.1244217

45. Thomas, K., \& O’Bannon, B. (2013). Cell phones in the classroom: Preservice teachers' perceptions. Journal of Digital Learning in Teacher Education, 30(1), 11-20.

46. Thornton P. \& Houser C. (2005) Using Mobile Phones In English Education In Japan . ED-Media.

47. Turloiu, A., \& Stefánsdóttir, S. (2011). Learner Autonomy Theoretical and Practical Information Ffor Language Teachers. DOI: skemman.is/stream/get/1946/7668/19634/1/

48. Walker, H. (2011). Evaluating The Effectiveness of Apps for Mobile Devices. Journal of Special Education Technology, 26(4), 59-63.

49. Yusri, I. K., Goodwin, R., \& Money, C. (2015). Teachers and Mobile Learning Perception: Towards A Conceptual Model of Mobile Learning for Training. Procedia - Social and Behavioral Sciences, 176(20 February 2015), 425:43.

\section{AUTHORS PROFILE}

Alsaif Sarah Ali M, Studying as student at School of Education, Faculty of Social Sciences and Humanities, Universiti Teknologi Malaysia, 81310 UTM Johor Bahru, Johor, Malaysia

Dr. Farhana Diana Deris, is a Senior Lecturer at the Language Academy, Universiti Teknologi Malaysia (UTM). She is currently the Manager of Partnership at UTM International. 